\title{
The Influence of Argon on the Deposition and Structure of Polycrystalline Diamond Films
}

\author{
K. Benzhour ${ }^{a, *}$, J. Szatkowski ${ }^{b}$, F. RozpŁoch ${ }^{b}$ And K. SteC ${ }^{b}$ \\ ${ }^{a}$ Department of Bases of Theoretical Biomedical Studies and Medical Computer Science, Collegium Medicum \\ Nicolaus Copernicus University, Jagiellońska 13, 85-067 Bydgoszcz, Poland \\ ${ }^{b}$ Institute of Physics, Faculty of Physics, Astronomy and Informatics, Nicolaus Copernicus University \\ Grudziądzka 5, 87-100 Toruń, Poland
}

\begin{abstract}
Thin polycrystalline diamond films were deposited on prepared (100) Si substrate by hot filament chemical vapor deposition using a mixture of hydrogen, propane-butane and argon. During investigations the gas flow of argon was varied from $100 \mathrm{sccm}$ to $400 \mathrm{sccm}$. Scanning electron microscopy analysis revealed that the addition of argon to the gas phase influenced the growth rate and film structure. An increase of argon concentration provokes an increase in film porosity and decrease in crystalline facetting. The quality of these films was investigated with the use of the Raman spectroscopy.
\end{abstract}

PACS numbers: 68.55.A-

\section{Introduction}

For practical applications of diamond films deposited by chemical vapor deposition (CVD), one requires thin diamond films with high crystalline quality, high phase purity and high growth rate. A mixed gas composed of methane and hydrogen has been used as feed gas in the conventional CVD method [1-4]. It is now well known that the growth rate of diamond films and nanodiamond carbon components in the diamond films were increased by argon additions. The addition of argon to feed gas could improve the crystallinity and quality of the diamond deposits [5].

In this work, we undertook a systematic study of the effects of the use of argon on diamond deposition in hot filament chemical vapor deposition (HF-CVD) varying the concentration of Ar in gas feed.

\section{Experimental}

The diamond films were deposited by HF-CVD method on the silicon (100) substrate. The substrate temperature measured by the thermocouple wire was $760^{\circ} \mathrm{C}$. The electrically heated tungsten filament positioned $6 \mathrm{~mm}$ under the substrate surface was used to activate the gas mixture. The pressure and flow of the gas mixture (propanebutane and hydrogen) were kept constant during all the deposition experiments (see Table I). The deposition time was about $24 \mathrm{~h}$.

\footnotetext{
* corresponding author; e-mail: benzhour@tlen.pl
}

TABLE I

Deposition process parameters.

\begin{tabular}{c|c|c|c|c}
\hline \hline Sample & $\begin{array}{c}\text { Propane- } \\
\text { butane } \\
\text { [sccm] }\end{array}$ & $\begin{array}{c}\text { Hydrogen } \\
\text { [sccm] }\end{array}$ & $\begin{array}{c}\text { Pressure } \\
\text { [Torr] }\end{array}$ & $\begin{array}{c}\text { Argon } \\
\text { [sccm] }\end{array}$ \\
\hline S1 & 6 & 400 & 20 & 100 \\
S2 & 6 & 400 & 20 & 200 \\
S3 & 6 & 400 & 20 & 300 \\
S4 & 6 & 400 & 20 & 400
\end{tabular}

The characteristics of the diamond films were examined using a scanning electron microscopy (SEM) and Raman spectroscopy (excited by $488 \mathrm{~nm}$ Ar laser line). Detailed studies of the Raman scattering measurements have been carried out in the range of $1000-2000 \mathrm{~cm}^{-1}$ and $1300-1370 \mathrm{~cm}^{-1}$, as both these regions provide information on the different aspects of the diamond growth process and the symmetry of diamond peak.

\section{Results and discussions}

\subsection{SEM analysis}

Figure 1 shows typical SEM images of as-deposited diamond films at argon concentration, taken in the central area of the samples. The SEM pictures show that for all samples the surface is continuous.

For samples S1 and S2 we observed that in the range of argon addition between $100 \mathrm{sccm}$ and $200 \mathrm{sccm}$ the diamond films present well-faceted crystalline grains, with a 


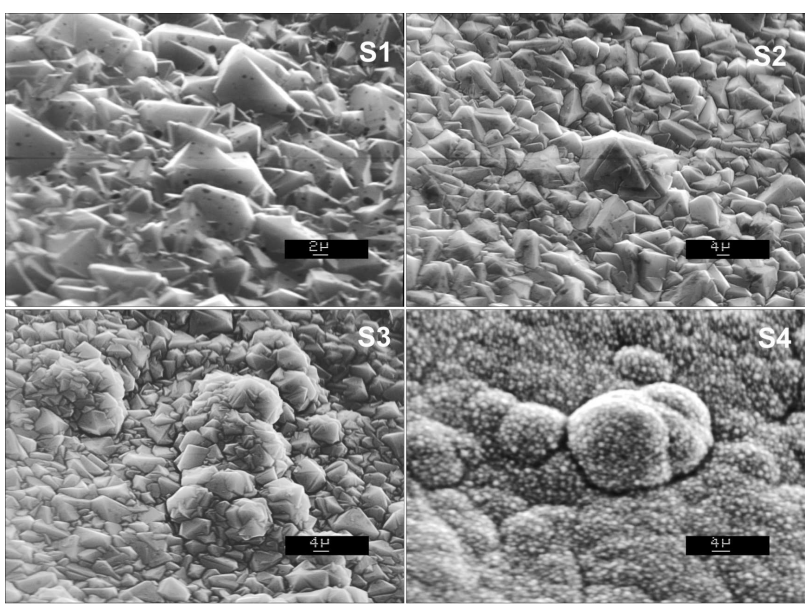

Fig. 1. SEM surface images of deposited diamond films.

predominance of angular shapes, corresponding to (111) crystalline surfaces. We also observed a decrease in the size of the grains.

Increasing the argon concentration in the feed, the morphology of the film begins to change drastically. There is a strong tendency to the formation of round and poly-faced grain (sample S3). If the argon concentration is very high, however, there is a complete loss of the crystalline facetting due to the large increase in vacancy defects and formation of graphite clusters that induce the deposits to be amorphous (sample S4).

Figure 2 shows the dependence of the diamond growth rate on the argon gas flow in the feed. It is observed that the growth rate increases with increasing argon concentration. The same form of the dependence of the growth rate on the concentration of argon was also observed for diamond produced by HF-CVD [5]. Also, similar effects have been observed with the addition of helium in a hot-filament reactor [6].

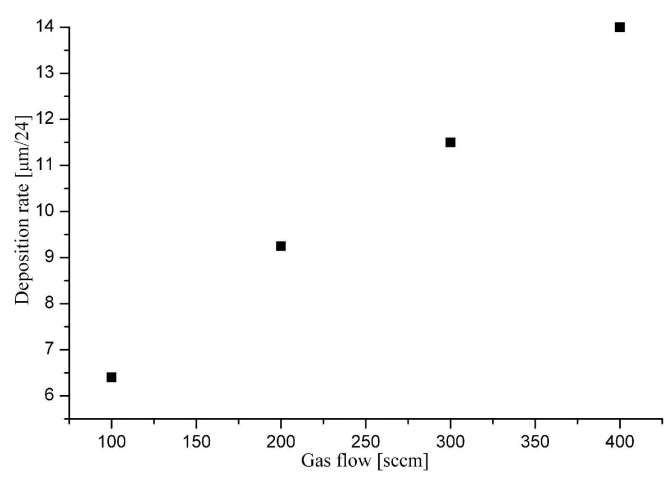

Fig. 2. The average growth rate of diamond films as a function of the argon gas flow.

The addition of argon provokes an increase in the dilution of the radicals formed at the filament. Owing to the characteristic chemical inertness of the noble gases, there is no reaction between the argon and the radicals formed, and, therefore, the radicals may have a higher lifetime, which increases the concentration of radicals at the growing film surface, resulting in an increase of the growth rate. Another important aspect is that the presence of inert argon may allow an increase in free carbon bonds not bonded to hydrogen in the gas phase, inducing an increase of the $\mathrm{C}$ concentration in the gas phase. The increase of the lifetime or the increase in carbon radicals and the increase in $\mathrm{C}$ concentration will contribute to the increase in the growth rate. However, at very high argon concentrations there is a lack of atomic hydrogen which impedes carbon deposition on the diamond phase [5].

\subsection{Raman spectroscopy analysis}

Figure 3 shows typical Raman spectra of samples grown at different argon gas flow. We observe that all samples present a peak at $1322 \mathrm{~cm}^{-1}$, which is characteristic of hybridized $s p^{3}$ bonds related to the diamond structure and a peak at $1560 \mathrm{~cm}^{-1}$ which is characteristic of hybridized $s p^{2}$ bonds related to the graphite structure. The parameters of $s p^{3}$ line are given in Table II.

TABLE II

Parameters of $s p^{3}$ line.

\begin{tabular}{c|c|c}
\hline \hline \multirow{2}{*}{ Samples } & \multicolumn{2}{|c}{$s p^{3}$} \\
\cline { 2 - 3 } & Line position $\left[\mathrm{cm}^{-1}\right]$ & Half width $\left[\mathrm{cm}^{-1}\right]$ \\
\hline S1 & 1333.1 & 10.267 \\
S2 & 1333.7 & 9.797 \\
S3 & 1334.8 & 9.364 \\
S4 & 1335.6 & 10.159
\end{tabular}

TABLE III

The values of stress estimated from diamond Raman line position.

\begin{tabular}{c|c|c}
\hline \hline Samples & $\begin{array}{c}\text { Line position of } s p^{3} \\
{\left[\mathrm{~cm}^{-1}\right]}\end{array}$ & $\begin{array}{c}\sigma_{\mathrm{D}} \\
{[\mathrm{GPa}]}\end{array}$ \\
\hline S1 & 1333.1 & -0.43356 \\
$\mathrm{~S} 2$ & 1333.7 & -0.67005 \\
$\mathrm{~S} 3$ & 1334.8 & -1.1036 \\
$\mathrm{~S} 4$ & 1335.6 & -1.41892
\end{tabular}

We observed a relative increase in peak $s p^{2}$ with an increase of argon concentration. Observations of the slope of luminescence curve on the Raman spectra make possible to explain the existence of defects in films.

The increase of $s p^{2}$ carbon phase in the diamond films should create internal stress. The internal stress can be estimated using theory developed by Rozpłoch and Fitzer [7], based on the harmonic oscillator approximation

$$
\sigma_{\mathrm{D}}=\frac{E_{\mathrm{D}}}{2}\left(1-\frac{\nu_{x}}{\nu_{0 \mathrm{D}}}\right),
$$

where $E_{\mathrm{D}}$ - Young's modulus for diamond (1050 GPa), 

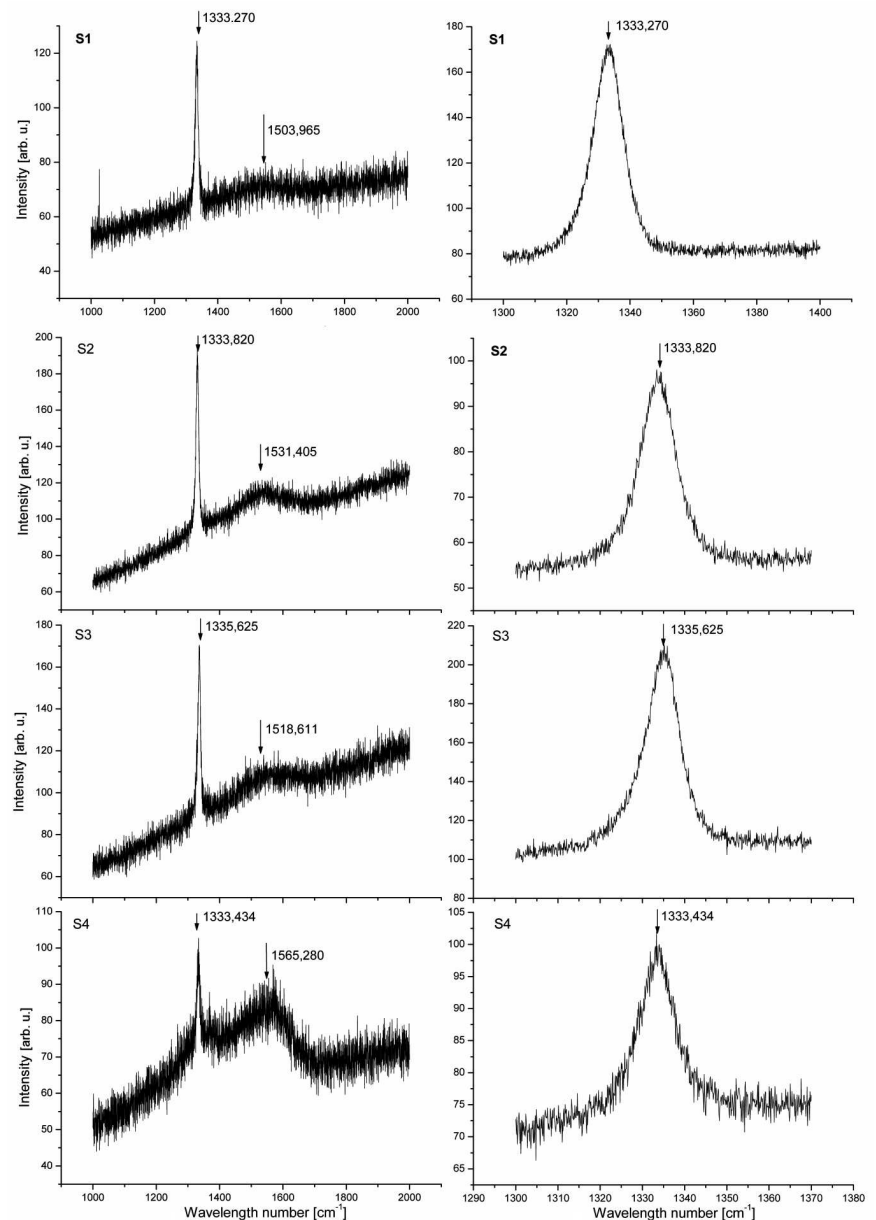

Fig. 3. Raman spectra of deposited diamond films.

$\nu_{0 \mathrm{D}}$ - the diamond line position $\left(1332 \mathrm{~cm}^{-1}\right), \nu_{x}$ - the measured diamond line position, $\sigma$ - the stress.

The results are presented in Table III. All samples show a compressive stress (negative). This type of stress causes diminution of the $\mathrm{C}-\mathrm{C}$ bond and the Raman line shift to the higher wave numbers.

\section{Conclusions}

This study has found that well-faceted diamond films are produced by hot-filament CVD using up to $200 \mathrm{sccm}$ of argon in the gaseous mixture $\mathrm{CH}_{4}$ and $\mathrm{H}_{2}$. The addition of argon induces an increase in the diamond growth rate. Baranauskas et al. [5] suggest that these results may be explained by the increase in dilution of the chemical radicals by an inert gas, such as argon. Radicals dissociated at the filament have a different kinetics than they would have if they were diluted in pure hydrogen, and thus may produce a greater concentration of free carbon bonds at the substrate surface. The inertness of argon also helps to increase the $\mathrm{C}$ concentration in the gas phase, which may increase the diamond growth rate or increase the deposition of graphite clusters.

The Raman analysis confirms that the faceted films grown up to $200 \mathrm{sccm}$ of $\mathrm{Ar}$, are of good quality diamond, while higher flows provoke an increase of other carbon structures. From spectra analysis we obtained different values of internal stress but for all samples we have compressive stress (blue shift).

\section{References}

[1] S. Matsumoto, Y. Sato, M. Kamo, N. Setaka, Jpn. J. Appl. Phys. 21, 182 (1982).

[2] A.R. Badzian, T. Badzian, R. Roy, R. Messier K.E. Spear, Mater. Res. Bull. 23, 531 (1988).

[3] J.C. Arnault, L. Demuynck, C. Speisser, F. Le Normand, Euro Phys. J. B 11, 327 (1999).

[4] S. Buhlmann, E. Blank, R. Haubner, B. Lux, Diamond Relat. Mater. 8, 194 (1999).

[5] V. Baranauskas, H.J. Ceragioli, A.C. Peterlevitz, M.C. Tosin, S.F. Durrant, Thin Solid Films 377-378, 303 (2000).

[6] V. Baranauskas, H.J. Ceragioli, A.C. Peterlevitz, M.C. Tosin, S.F. Durrant, Thin Solid Films 377-378, $182(2000)$.

[7] F. Rozpłoch, E. Fitzer, High Temperatures-High Pressures 20, 449 (1988). 